\section{THE DIGITISED PUBLIC SPHERE: RE-DEFINING DEMOCRATIC CULTURES OR PHANTASMAGORIA ${ }^{1}$}

\begin{abstract}
Does an increasingly interconnected world provide new opportunities for civil society to enhance democratic practice - or are human relationships diminished and emptied of their vitality as carefully constructed online profiles proliferate? Debates have emerged about the efficacy of a digital democracy and its ramifications for public politics. This paper follows the specific argument concerning some

of the claims from online proponents of the potential of the Internet to create a more informed and accountable democratic culture. It is concerned with questions of the transmission of values and some of the cognitive aspects of this technology. Some techno-futurists are in no doubt concerning the political implications of a more interconnected age; others are more sanguine about the intrusiveness of this new technology. For example, there are numerous claims concerning the potential for Internet-based forums to enrich democratic practice, of breaking-down sovereign borders and establishing a pluralistic transnational global public sphere. On the other hand, political realists are skeptical of new communications technology and its potential to transform democratic life, which is still essentially embedded in the polity of nation states. This paper does not add to this burgeoning literature, but rather focuses on "democratic values" by posing questions about "digital democracy" and whether or not this new technology is leading to greater levels of public participation, social inclusion and empathy.

The article concludes with questions and considerations about language, thought and judgment, and whether or not this latest transformation of the public sphere and new experimentation with novel forms of communicative action, fundamentally alter our traditional conceptions of the intersubjective basis of political reasoning.
\end{abstract}

Peter Marden is Senior Lecturer in the School of Global Studies, Social Science and Planning, RMIT University, Melbourne; e-mail:

peter.marden@rmit.edu.au. 
In a little book preceding the Internet age and the age of Ipods and mobile phones, Neil Postman argued in Amusing Ourselves To Death (2005) that we are in constant need to be stimulated, and the electronic media is well equipped to deliver. In the Introduction to the Twentieth Anniversary Edition, Postman's son argues that the questions raised by his father are still relevant today. What happens when we become infatuated with and then seduced by technologies and media? Do they free or imprison us? Do they improve or degrade democracy? Are our leaders more or less accountable? Postman's concern was with how this need combined with the saturating power of the visual media corrodes a public language; a democratic discourse is being reshaped before our eyes. Streams of data and visual frames dominate without much time to think, to critically reflect on the social world we all inhabit. Postman produces a lively polemic about technology without falling into naïve determinism. His main concern was television because as he argued it "offers viewers a variety of subject matter, requires minimal skills to comprehend it, and is largely aimed at emotional gratification" $(2005,86)$. He further argued that the problem is not that "television presents us with entertaining subject matter but that all subject matter is presented as entertaining, which is another issue altogether" $(2005,87)$. The expanded digital horizons brought about by the advent of the Internet and telecommunications technology generally over recent decades has added a new dimension to Postman's lament. The advent of corporatised media, the dumbing down of journalism, the rise and rise of reality television, and the presentation of war as spectacle such as the "shock and awe" campaign, reinforces and vilifies Postman's argument. It would appear that the worst of all dilemmas in this modern age is the onset of boredom, technological innovation ensures constant business. Some techno-futurists are in no doubt concerning the political implications of a more interconnected age; others are more sanguine about the intrusiveness of this new technology. For example, there are numerous claims concerning the potential for Internet-based forums to enhance democratic practice, of breakingdown sovereign borders and establishing a pluralistic transnational global public sphere. On the other hand, political realists are skeptical of new communications technology and its potential to transform democratic life that is still essentially embedded in the polity of nation states. This paper does not add to this burgeoning literature, but rather focuses on "democratic values" by posing questions about "digital democracy" and whether or not this new technology is leading to greater levels of public participation, social inclusion and empathy?

\section{Communication Breakdown?}

It is easy to slip into a neo-Luddite frame of mind and simply present people as if they are passive victims of technology. However this is not the case here. Having the means to communicate more and more does not directly translate into actual communication involving the skill of listening to others. The archetypical example is the advent of electronic mail - email. This instantaneous technology of allowing us to communicate messages to each other from all over the world is of course an exciting development with incredible practical purpose. This has truly annihilated distance as any sort of barrier to the written word and is faster than faxing. Yet the daily grumbles are present among the users: too much spam, too many unwanted questions from unknowns, too long to answer all emails, the abuse from those 
who expected your speedy reply, and so on. The text has truly become dominant as more of us choose to shut the door and send an email than actually talk to the person we are communicating with, even to colleagues across the hall. What communication skills are we fine tuning with this technology? What lies ahead for the gentle art of conversation and rhetoric, of listening to a human voice with all of its nuanced expressions? Yet, it enables distance and space and protects those who need to deliver unpalatable news. It is also a useful portal for many to engage in textual communications with individuals and corporations unfettered by the usual social conventions. Beyond those practical advantages what virtues does email hold? Is the unopened email a reminder of the demanding presence of the Other, or just another stinging gadfly daring to interrupt your sense of self? Perhaps this is why we are beginning to see more and more "email free zones" emerging out of cyberspace, as well as the increasing number of technological curmudgeons simply refusing to reply to your email?

The world of Internet-based research also needs careful scrutiny as to its relation to scholarship and public education. Are we not witnessing a more democratic medium where people can access a greater number of knowledge sources and information at the click of a button? If in a deliberative democratic sense we are genuine in our desire to reach more people, and to expand the opportunities for engagement and participation, then online technologies should be celebrated as an integral transmission vehicle for ideas and robust debate? The printing press contributed to the speedy decline of Latin, does the online world also undermine traditional methods of conveying information? For those steeped in the virtues of careful scholarly research, the declining patronage of public libraries would seem a disturbing phenomenon. The debate is ongoing between professional writers, researchers and academics in general concerning the virtues of placing research articles online, rather than follow the traditional path of journal publication. Making academic work more publicly accessible has many advantages because as the community becomes less inclined to visit a library, look for the hardcopy journal, as opposed to using search engines like Google Scholar - an expansion of readership is ensured. Various studies have shown that making articles available online boosts citations by 50 per cent to 250 per cent, yet only about one-seventh of the research conducted by Australian academics is freely available on their websites. There is a persistent belief or at least scepticism among many academics that the quality of scholarship is somehow determined by the medium. Are there not bad articles in good journals? Publishing on the Internet does not necessarily mean that research standards are somehow suspended, or that the same rules for evidentiary-based argument are not present.

This last point raises a few anomalies concerning the public intellectual, for the want of a better term. Scholarly tradition dictates that research publications require peer review and those un-refereed articles are not afforded the same intellectual respect, yet many can inform public debate. Indeed, in most Australian universities, "non-refereed" articles are usually not weighted at all under the Federal Government's formula. Subsequently, research irrespective of its contribution in various forums to the stimulation of public debate and engagement can be ignored completely by a system aligned with a small coterie of "experts" who place a value on knowledge by peer review. Under the present system in Australia, a hundred 
articles to newspapers and other public forums will not accrue the same "points" as two leading articles in respected national or international academic journals. However, the emergence of the "blog" has provided opportunities for writers to capture a broader audience and to encourage genuine dialogue. The number of blogs (a form of Internet journal that allows you to post articles daily or weekly) has grown exponentially during the past five years; there are tens of thousands of blogs in Australia and millions worldwide (Leigh 2006). The upside of academic blogging is the chance to engage with non-specialist and colleagues on issues of your choice without the dictates of journal conventions and expectations, it encourages a freer form of writing, perhaps a more normative laden discourse not made tentative by the rigors of first-person obsessions. They can be used as a teaching tool with additional readings posted so as to cultivate a wider interest in the subject matter, particularly among students. The downside can be the time consuming effort of posting weekly or daily entries, debating with commentators and everything else that distracts you from further research or from the "resubmit" sitting on your desk. Notwithstanding, the lure of the Internet as the "world's library" is becoming more intense each day, in which case it may turn out to be the only truly democratic forum left.

As with all democratic forums, there is much to hamper this electronic agora in any quest to establish a progressive pluralism of political voices. We are all too familiar with the "nasty" websites and hate-speech forums of cyberspace to be carried away with the positive potential of this technology. It has become a modern form of "bread and circuses" with the capacity to satisfy a wide range of anti-social pursuits, from computer games rewarding racial violence to chat rooms and blogs catering for the zealot and the fanatical. The combination of other fears such as the surfing paedophile, viruses, hackers and the easy access to a plethora of pornographic sites, all makes one a little uneasy about the vision splendid of a citizen-designed and controlled communications network. As Hannay $(2005,126)$ so aptly observed we are in our own constant verbal flight from our surroundings:

We vanish into talk shows, reality television, and the time spent doting on the web-sited preparations for the marriages of celebrities. By unresistingly grasping the now vast opportunities offered by the media for voyeurism and illusions of intimacy with the great, we even appear to accept that we are nothing if not in the company of these "true" human beings.

These verbal flights are intensified with the constant mobile-phone user. On the surface, people are in constant conversation, either through voice or SMS texting, which has also become hugely popular. For example, text messaging is the domain of the young: on an average day in Australia, less than a quarter of Australians will send a text message, and only three per cent of people aged 60 and over will use SMS, but nearly two-thirds of people aged 18 to 29 will use SMS. Moreover, one in four children aged from 6 to 13 now have a mobile phone. More than 90 per cent of children aged from six to nine have used a mobile phone, usually one belonging to their parents (DCITA, 2005). This report also highlighted that the age-group 18-24 were the heaviest users, but there was also a strong trend amongst young middleclass professional men. But Hannay questions whether this new form of communication explosion is the medium for true dialogue. "They are mutant monologues designed to 'fill' time; they provide a way of speaking to yourself that relieves you of 
half the trouble of finding your own words" $(2005,126)$. Hannay further argues that is the nuances of speech and the art of listening, especially in public space, which is being transformed, "silences that are part of normal conversation and integral to what is imparted aloud are impossible; the mobile phoner's "space" has to be constantly filled or else you have to keep on saying, "Are you still there?" What, if any, significance do we place on silence? In antiquity, Horace referred to silence as being "sacred" while Plutarch proposed that silence is something "profound and awesome," Comte on the othetr hand argued that "conspiracies of silence" are complicit in forms of social exclusion (Burke, 1993).

Are we living as some postmodernists argue on hyperreal surfaces awash with trivia, gossip, small-talk as we make our way through the consumerist fog? If so, what has happened to speech, to conversation, to listening and what if any impact does this have on our ability to judge and to make judgments in the political realm? Does the speed at which we access information and exchange views improve or detract from our ability to think critically? In Arendt's critique of modernity the world created by homo faber is threatened with extinction by the "rise of the social." The activity of work and the consumption of its fruits, which have increasingly come to dominate the public sphere, cannot produce a common world within which humans might pursue their higher ends. Surely it is safe to assume that Arendt's observations and words written in the 1950s are even more appropriate today with the aforementioned technological innovations. Arendt argues that it is a mistake to take freedom to be primarily an inner, contemplative or private phenomenon; conversely it is active, worldly and public. Our perception of an inner freedom is derivative upon first having experienced "a condition of being free as a tangible worldly reality. We first become aware of freedom or its opposite in our intercourse with others, not in the intercourse with ourselves" $(1993,148)$. Arendt's theory, derivative of Kant's thought, holds that actions cannot be justified for their own sake, but only in light of their public recognition and the shared rules of a political community. As free-acting members of a political community we seek to impress and persuade each other through speech and deed; at the same time we listen to others and make ourselves available to persuasion, we evaluate and weigh the meaning and quality of others' words, acts and propositions - in short we are called upon to judge and be judged. Hence, Arendt arrives at an account of judgment as a political faculty which construes it as public, intersubjective, communicative, persuasive, empirically/phenomenally oriented, plural and tending towards certain universality (Yar 2000). I am unsure as to how Arendt would judge the communications technology of the 21st century and its capacity to finely tune this political faculty? How indeed do we judge the "blog," which as an Internet forum is growing exponentially? Whatever the outcome, people are coming together in cyberspace to discuss ideas and initiate polemic over ideals; amidst all the narcissistic pornographic sites this new cyberspace "public" may provide the capacity for participating citizens to think, judge and act accordingly - or provide the means to simply amuse ourselves to death.

As with all debates concerning technological innovation there are serious questions about impact that need attention. There are numerous Luddite type criticisms one could locate based on rather simple premises of anti-technology that broadly translate into statements about progress. However there are other concerns, which 
seem to be supported by considerable research and evidence around the issue of cognition and cultural change, which are gaining intensity. The ability to think and to use critical faculties is of crucial importance to enriching a public culture. Information technology annihilates space and the idea of an electronic/wireless agora is a concrete reality, as for the first time an unprecedented number of people are interconnected across the globe. The advent of social networking and its associated platforms is, at least for some social and political commentators, leading to increased democratisation. What is "social networking?" Petersen (2010) describes it as a term, for all its vagueness, that refers to an online community, an online sharing experience that may include: the creation of a webpage or "profile" which serves as a "surrogate home" for the self; participation in a "virtual agora" where you can stroll through landscapes and communal settings and meet with others, or simply observe strangers; and lastly, an ability to remove the digital barrier and reveal yourself to subjects of your gaze by "friending" them (a request to be connected online in some way).

The growing popularity of Facebook and Twitter is a clear indication that people like sharing and collaborating. For example, Shirky (2010) argues that these architectures of participation encourage generosity and participation which "enriches us all." Unlike mediums of passive consumption such as television, these Internet technologies turn us from passive consumers into active producers and sharers of content. In sum, the Internet is creating a better, more democratic world (Chatfield, 2010). The increasing pace of innovative social network portals has lowered the cost of collaboration and revolutionised new kinds of creativity and problem solving. Thus, according to proponents like Shirky, the world's collective "cognitive surplus" is being put to transforming uses. A different mass culture is emerging based on varying levels of active participation involving processes of searching, doing, sharing, making and modifying. The importance lies in people becoming active in the creation of content rather than simply being receivers, and this can potentially produce a critically informed public. A broader but related question emerges: is there a new language of politics evolving? George Steiner once said in a BBC interview that we have to adjust to the fact that there is a new literacy forming around us at great speed. Historical precedence has established that writing undergoes transformation as the printing press bares witness. The lament of older English professors is that writing and reading as acquired critically reflexive skills, is rapidly eroding and technology is to blame. Together, Facebook, Twitter and PowerPoint have produced narcissistic blabbering and "dehydrated language into bleak bald," sad shorthand (Thompson 2009). Opposing such a view however, is Lunsford, a professor of writing and rhetoric at Stanford University who argues that, "we're in the midst of a literacy revolution the likes of which we haven't seen since Greek civilization." Lunsford believes that rather than eradicating our ability to write, new technology is reviving it and pushing literacy into new directions (see Thompson, 2009). This argument is premised on the realisation that young people socialise online which invariably involves text. Lunsford further argues that this "paradigm shift" is reminiscent of what rhetoricians call kairos - assessing their audience and adapting their tone and technique to their best advantage. Hence, the modern world of online writing is conversational and public, which is representative of the Greek tradition of argument (Thompson 2009). A public language 
is formed based on writing to an audience and involves active participation in the form of intersubjective texting, reading and thinking.

\section{To Be Everywhere Is to Be Nowhere (Seneca)}

Some of the enthusiastic proponents of Internet technology make some remarkable claims that require critical attention in terms of their meaning and implications. One good example again comes from Wired's Clive Thompson $(2007,1)$ :

I feel much smarter when I'm using the Internet as a mental plug-in communicate, because I continually stud my IMs with links, essentially impregnating my very words with extra intelligence. You could argue that by offloading data on to silicon, we free our own gray matter for more germanely "human" tasks like brainstorming and daydreaming. What's more, the perfect recall of silicon memory can be an enormous boon to thinking.

The problem however is that when knowledge is transferred as shorthand the ability to adequately analyse complexity and nuance is problematic. When confronted with the real-time web's constant flow of incoming information, who has time for factual detail? The information floodgates are open but how finely tuned are our discretionary filters and cognitive processes? Nicholas Carr (2010) argues that there is increasing scientific evidence that the net with its constant interruptions is turning us into scattered and superficial thinkers, hungry for stimulation and the lure of perpetual distraction. We are, Carr argues, surface dwellers lumbering around in the shallows picking up bits and pieces of information which is hampering our ability to focus and engage in deep reflective thought. Sunstein (2001, 1) argues that the ability to "filter" information narrows rather than broadens the information horizon of many users. He refers to this process as "personalisation," which limits the information horizon of many users. "They filter in, and they also filter out, with unprecedented powers of precision." Sunstein $(2006,89)$ further argues that the "internet is making it possible for people to design their own highly individuated communications packages, filtering out ... disfavored voices." Carr offers an exploration of the intellectual and cultural consequences of the Internet with a clear message that every information technology carries an intellectual ethic, a set of assumptions about the nature of knowledge and intelligence. Carr also refers to some disturbing cognitive issues arising from this digital media, which are changing the way we actually think. Carr (2010) further draws our attention to some important research from neuroscientists arguing that the cellular structure of the human brain adapts to the tools we find, store and share information. By altering our habits of mind, every new technology strengthens certain neural pathways while weakening others. These changes shape the way we think, even when we are not in front of a computer screen. The leading neuroscientist, Michael Merzenich argues that our brains are being "massively re-modeled" by our increased use of web related media (Carr, 2010). The cognitive consequences of perpetual distraction may have a "deadly" long-term effect on the quality of our intellectual lives. What seems to be at risk is the capacity to engage in quieter, attentive modes of thought that is fundamental to contemplation, reflection and introspection. As Carr $(2010,13)$ astutely comments: "the cacophony of stimuli short-circuits both conscious and unconscious thought, preventing our minds from 
thinking either deeply or creatively. Our brains turn into simple signal-processing units, shepherding information into consciousness and then back again." So at the heart of this phenomenon is our ability to think, and for millennia philosophers have rightly or wrongly assumed both an abstract and practical rationality as the basis for this capacity. Moreover, making judgments about politics and the "good life" is a faculty driven and shaped by the act of "thinking." To what extent do we need to revive and modify these traditional positions?

Almost a decade ago, Gordon Graham (2000, 77-83) in his philosophical inquiry into the Internet concluded that, "we may expect the Internet to be transforming. It will not, however, transform political life along more truly democratic lines." But rather than enhance democratic culture it may "strengthen the downside of democracy which has a tendency to favour consumer politics over rational decision-making." In line with some narcissistic observations about modernity, he further argues that the Internet, "will strengthen rather than weaken the atomising character of individualism because it encourages moral fragmentation." In what seems to be a liberal apologia Graham may be accused of indulging in a nostalgic dreamtime but this would be a rush to judgment and a misrepresentation. The warning is not about new technology but our relationship to vast repositories of knowledge as a guide to action and practical reason about our relations with others. In a recent interview, Seyla Benhabib (2008) within the context of the question "does Arendt matter today" recognises that the Internet is an important new medium that facilitates public interaction. However, it also fails to satisfy some of the demands implied by Arendt's concept of public politics. Within the world of cyberspace, mutual understanding and acceptance are not necessarily facilitated, in particular because anonymity is possible. Like Graham, she argues that although a vast world is at our fingertips we also have fewer obligations to communicate in person, which is causing increased fragmentation. Arendt expects our interactions with the public sphere to be experiences where we learn from taking the perspectives of others and stepping outside of the personal. The problem it would seem is that the public has become deeply personalised.

The key questions seem to be around the issue of content and the constitution of the "social digital democratic" world. As a marketing tool the new social networking media is growing in importance, in parallel with the extent of corporatisation of what is widely perceived by the public as free and open space for participation. It is somewhat ironic but the bulk of research done on this aspect of digital networking is located on the net itself. This reality reinforces the potential for Internet-based information to be readily utilised by writers to inform debate and extend research. Of course, this of itself is not necessarily a negative development, but rather represents a source that requires steadfast critical scrutiny. The fact remains, the creeping pervasiveness of markets and profit are eking their presence on the digital world, particularly through interactive advertising and marketing. Much of our online experience, from websites to search engines to social networks, is being shaped to better serve advertisers. To an alarming extent, individuals are being electronically "shadowed" online, our actions and behaviours observed, collected, and analysed so that we can be "micro-targeted." Now a $\$ 24$ billion a year industry [2008 estimates] in the U.S., with expected dramatic growth to $\$ 80$ billion or more by 2011, the goal of interactive marketing is to use the power of 
new media to deeply embed users in the multifarious products and services being sold (Clark 2009). In what the industry termed the "mobile marketing ecosystem," corporations and specific groups are actively targeting children, adolescents, and multicultural communities. Mobile marketers in the U.S. are already deploying an array of targeted marketing strategies, involving so-called rich media, mobile video, branded portals, integrated avatars that offer "viral marketing" opportunities, interactive and "personalised wallpapers," "direct-response" micro-sites, and a variety of social media tracking and data analysis tools. It is likely that many users do not fully understand the privacy implications of every discount coupon, free download, or ringtone offer that comes their way. What happens to information in this digital age? As Clark (2009) argues, much of this information is entered into or captured by an intelligent preference engine that uses sophisticated statistical techniques and predictive algorithms to determine the optimal content or offer on an individualised basis.

Another shadow cast by this public technology is the very antithesis of democratic civility, antisocial behaviour. There is mounting evidence that the presence of cyber bullying is on the rise, indicating the uncivil nature of social networking and mobile communications. In 2007 a survey of 45,000 children in the United States revealed that 85 per cent of children between the ages of ten and fourteen had experienced cyber bullying. But the problem is not unique to the United States as it is also a growing problem in Australia. The number of reports of cyberbullying to the NetAlert Helpline has been increasing, particularly since 2006. An online safety survey conducted by NetAlert and ninemsn in February 2007 found that: 16 per cent of young people said they had been bullied online, while 14 per cent were bullied through their mobile, with boys and girls experiencing similar levels, and 56 per cent thought it was easy to get bullied online (ReachOut 2010). The Australian Covert Bullying Prevalence Study (Cross 2009) was commissioned by the Australian Government and conducted by the Child Health Promotion Research Centre at Edith Cowan University. The study highlighted the growing problem of covert and cyber bullying affecting Australian schools and their students. Results from this study identified age trends in the occurrence of covert and cyber bullying. For example, 65 percent of Year 4 students experienced covert bullying, with this number decreasing to 35 percent of Year 9 students. Up to 10 percent of students in Year 4 to Year 9 reported having been cyber bullied in the previous term, with older students in this age category reporting a higher rate of victimisation than younger students.

The social history of technology offers numerous examples of "darksides" so there is little surprise to this current phase. However, the primary cosmopolitan assumption that greater interconnection will also foster a greater tolerance and compassion for others, is seriously tested with the endless pluralistic worlds of cyberspace. While forms of digital communitarianism are clearly evident there are powerful countervailing forces of social and political fragmentation, of vivid examples of "group think" and dubious conformity to like- minded causes. Can we seriously define a digital public sphere and practices of constructive deliberation? Or indeed, many contested publics? The scholarly debate is gaining momentum with this question, but quite often not enough attention is given to the values underpinning democratic culture. The emphasis appears to be on the extent of par- 
ticipation, in which the Internet has certainly expanded, but rarely on the nature of this participation. In his rigorous investigation into the democratic potential of the Internet, Matthew Hindman (2009) makes an important contribution to this debate. As a counterpoint to his basic argument however we first should posit what many proponents argue, such as this comment from Gabbard (2006):

We shudder to think about where the progressive movement would be today in the absence of a free and open Internet. In no small measure, the Internet has become our new public forum, an electronic town commons. As investigative journalism has died a quiet death in the hands of corporate media conglomerates, independent bloggers have displaced newspaper, radio, and television reporters as the muckraking journalists of today. Blogs enable common citizens to share information, ideas, and opinions free from government or corporate censorship. The Internet has triggered its own electronic Enlightenment and democratic Renaissance, mobilising people to organise and resist the plutocratic and autocratic control of the corporate state.

While I have some sympathy for Gabbard's point, especially the potential for a genuine public forum to exchange views and information, the corporate structural impediments to this "renaissance" are not readily identifiable. Hindman argues that contrary to popular belief, the Internet has done little to broaden political discourse but in fact empowers a small set of elites - some new, but most familiar. He argues that, though hundreds of thousands of Americans blog about politics, blogs receive only a miniscule portion of Web traffic, and most blog readership goes to a handful of mainstream, highly educated professionals. Hindman observes that despite the wealth of independent Web sites, online news audiences are concentrated on the top twenty outlets, and online organising and fund-raising are dominated by a few powerful interest groups. He brings a necessary candid critique of the supposed "independent autonomy" often expressed by proponents of this virtual community. In his empirical studies, he tracks nearly three million Web pages, analysing how their links are structured, how citizens search for political content, and how leading search engines like Google and Yahoo direct traffic to popular outlets. He concludes that while the Internet has increased some forms of political participation and transformed the way interest groups and candidates organise, mobilise, and raise funds, elites still strongly shape how political material on the Web is presented and accessed.

Hindman's (2009) work is particularly useful because it avoids the nostalgic trap of an anti-technological rant, or some neo-Luddite manifesto, but rather offers a critique of sites of power that are often hidden or taken for granted by many users. How exactly is political information shared? He draws our attention to a rather old, yet important term within the discourse on media, namely, the role of "gatekeepers" and the "gates" themselves. He counters the often-repeated claims of proponents that online communication is egalitarian just because the architecture of the Internet is open and decentralised. The assumption rests on the belief that the Internet eliminates traditional gatekeepers, and gives voice to marginalised or resource-poor groups. He comments, the "Internet is not eliminating exclusivity in political life; instead, it is shifting the bar of exclusivity from the production to the filtering of political information" [author's italics] $(2009,14)$. More attention should be paid to the technological architecture of the Internet and the role of the 
"search engines" that guide and powerfully limit most users and shape online search behaviour. To this end, Hindman argues that the Internet is changing the processes and technologies that support mass political participation and guide elite strategy. One important outcome is that changing the infrastructure can alter patterns of participation. The whole notion of free and open Internet space is seriously flawed. With specific reference to the United States, Hindman suggests that a "broad conception" of what constitutes the Internet's infrastructure should be adopted: the topology of hyperlinks, as well as the major search engines and their rankings of relevance to various search queries should be considered part of the backbone infrastructure. Such a broad conception works against the notion that the Internet is a relatively "flat" medium in terms of equal participants. He points out that despite the appearance of a multitude of political sites where citizens can randomly access and engage, barriers do exists which ensures that the chances of actually being read on the Internet is astonishingly small. The enabling capacity of the Internet for direct political speech is limited and does not follow egalitarian patterns. Politically related web traffic is concentrated to a few big outlets, and while there are a very large number of web sites with tiny audiences, there are very few web sites with moderately sized readerships. According to Hindman $(2009,142)$ political communication online follows a winner-takes-it-all pattern: "It may be easy to speak in cyberspace, but it remains difficult to be heard" (cited in Blomberg, 2009).

The clear pattern Hindman wants to draw our attention to is the increasing commercialisation of the Internet, and the corporatised hierarchies that exist within the architecture itself. What could be perceived as a criticism of deliberation theorists, he highlights the dubious assumptions of their enthusiasm for plural spaces, and the underlying belief in that once the barrier to participation is overcome, citizen voices are considered relatively equally. His empirical research shows that political expression online is orders of magnitude more unequal than the disparities we are familiar with in offline practices such as voting and volunteer work. The volume of online content shapes certain online behaviour whereby citizens seem to cluster strongly around a relative few information sources in any given category. The increase in traffic to top sites coincided with greater institutionalisation and commercialisation in the online public sphere. Hindman refers to the "professionalisation of the blogosphere" as an inevitable phenomenon of market forces, ultimately leading to a concentrated hierarchy of portals under the control of old and new media organisations. Moreover, far from opening up space for a broader participatory citizenry, this domain is preponderantly elite driven by highly educated professionals. As with all types of public mass participation there are cosmopolitans who openly engage and debate with those of different views and experiences, and those who are deeply polarised and tend to attach to like-minded groups. People are still making discrete choices as to what websites and blogs they engage, so in this sense it is no different to face-to-face networks. The implications however is that the evidence seems to suggest that the "networked public sphere" is not necessarily transforming participation in an enriching deliberative way by promoting civic argument and debate, as argued by Benkler (2007) and others. Rather, it is more representative of what Sunstein (2001) calls "balkanisation" of different groups "into separate universes of discourse" fed with "erroneous information cascades." Farrell (2008) 
also argues that here is strong evidence of ideological polarisation among bloggers and that anonymity creates both agreeable and disagreeable zealots.

\section{Conclusion: From Facebook to Virtual Democracy}

I have deliberately chosen the dark side of social networking and its implications for nourishing a democratic culture, mainly as a counter to the pervasiveness of Internet utopian thought. Referring back to where I began with the previous work of Postman, the question remains valid: are we amusing ourselves to death? Consumerism and market saturation are grise for the mill for any political theorist and social commentator concerned with political values and the future of democracy. This is a many-sided scholarly debate and in due recognition of the importance of "value pluralism" this is encouraged in any normative discourse. Despite the advances in interconnected co-operation I am more concerned about thought and language, and how we maybe loosing a critical capacity for building a democratic culture based on a humane understanding of difference and a broad recognition of the pluralism of values.

In an era prior to the emergence of social networking as is currently practiced, Sandbothe (1999) reflected on the works of Rorty and Derrida on concepts of time and language, with specific reference to the Internet. Rorty's hope is that with the help of [new] media we might succeed in bringing together groups of people who have grown up in different social, political and geographical cultures and with varying views by "linking through a thousand small stitches and ... conjuring up a thousand small similarities" (Rorty cited in Sandbothe 1999). This cosmopolitian vision, one that understands "moral progress in the sense of increasing sensitivity and growing receptiveness for the needs of an ever increasing multitude of people and things' can be directly related, according to Sandbothe (1999), to the "transcultural communications practices, which are characteristic of virtual communities in the Internet." Sandbothe (1999) goes on to refer to the earlier work of Pierre Levy, in particular his book Collective Intelligence: Mankind's Emerging World in Cyberspace (1997) in which he described the Internet as "the creation of a new medium of communication, thought, and work." Levy goes on to argue that this media will "enable us to think as a group ... and negotiate practical real-time solutions to the complex problems we must inevitably confront" (1997: XXVII, cited in Sandbothe, 1999). The prediction here was that "communities of common interest" will emerge as opposed to communities of proximity and this will assist in the formation of transgeographic communities and transcultural solidarities that in turn will produce interactive networks and forms of communication which facilitate the emergence of transversal, interest-based communities. This rather optimistic tone is clearly not evident in what has been discussed previously, although nobody can deny the clear presence of numerous websites dedicated to open transparent attempts to speak truth to power. If what was proposed by Sandbothe (1999) has come to fruition over the recent decade, it has been countered by the growing commercialisation of this networked public sphere. What is the actual evidence of "transcultural solidarities" making for a more participatory democratic culture outside of specific like-minded interests? The Internet is currently a medium replete with "interest groups" from the far Right to the far Left, if such dichotomies can still be applied. It is therefore a medium by which has grown a diversity of interests with little evidence of any 
attempt to deliberate and negotiate through differences and contrasting values. Platforms such as Facebook may have reconfigured the architecture of communication and instilled a new online vocabulary, but what are the real gains in terms of enriching political life and civic relations?

What is the appeal of Facebook and Myspace that usage worldwide is now compellingly high? Facebook, with the private information of over 350 million members, now constitutes what Wired magazine has called a "second Internet." According to Petersen (2010) Facebook's continuing attraction comes from its ability to reduce the Internet's worldwide chatter to the size of a university campus, or a village, or a living room. Bringing the world into the home takes on new meaning through the globality of the deeply personal and a transcendence of intimacy. William Deresiewicz (cited in Petersen, 2010) argues that friends are being turned into an indiscriminate mass, a kind of audience or faceless public, and that friendship is devolving from a relationship to a feeling. Petersen refers to the "Facebook Generation," as "digital natives" and laments as one born well-before the Internet juggernaut whether these "digital natives" will ever know the "true sweetness of privacy." As Bourdieu has often reminded us, intentionality and practice are critical in our analysis of why and how things happen. Online behaviour is obviously as complex as real-world interaction and individuals are motivated by various intentions. One cannot dismiss the leisure ideal in that drawing conclusions about the politics of community and democracy from what maybe interpreted as leisure activity. This may demand a sociological understanding of increased participation of online leisure activity without any specific political intentionality. The popularity of online gaming for example cannot be associated with a form of democratic deliberation for political ends, but rather another example of civil societal experimentation with new technology. The virtual world is alluring and offers a richer and more interesting experience than the drudgery of everyday life, and although excessive duration of uninterrupted play may be analogous with narcotics and a narcissistic endeavour, it does not necessitate a substitute for political interaction.

The question remains however: does an increasingly interconnected world provide new opportunities for civil society - a society which links people globally - or are human relationships diminished and emptied of their vitality as carefully constructed online profiles proliferate (Sager 2010)? Debates will continue about this question and its ramifications for public politics. In this paper I have followed the specific argument concerning some of the claims from online proponents of the potential of the Internet to enhance and produce a more informed and accountable democratic culture. I have concerned myself with questions of the transmission of values and some of the cognitive aspects of this technology. There are other dimensions to this argument that I have avoided simply as a matter of scope and size restrictions, but they are worthy of mention at this late stage. One critical dimension is the freedom of speech and the exposure of state secrets brought to global significance with the phenomenon of WikiLeaks and the ongoing plight of its founder, Julian Assange. The significance of this for democracy is worthy of a singular focus, one that is beyond the scope and intent of this paper. I am nevertheless strongly supportive of the capacity of the Internet used this way for the value of truth and political accountability to be upheld for the public interest, an imperative for any working democracy. Another dimension, only touched upon here, are considerations about language, thought and judgment, and whether or not 
this latest transformation of the public sphere and new experimentation with novel forms of communicative action, fundamentally alter our traditional conceptions of the intersubjective basis of political reasoning. What practical outcomes can we envisage about democracy and the practice of deliberation as a viable discursive space? What constitutes everyday communicative practice, and which value judgments are true or false in given situations?

The issues raised earlier by Carr (2010) are integral to the most practical, yet paradoxical feature of an Internet transformed public sphere: how are we to think? As Waldron (2007) points out, the nature of thinking is one of the most important concerns of Arendt's social and political theory. Thinking is the "habit of examining whatever happens to come to pass or to attract attention" in inner dialogue, in a sort of conversation with oneself, where every mental reaction is subject to criticism and in which the inner critic is also held to answer back and forth. Arendt speculated that, in many circumstances, moral conduct seems to depend on this "intercourse of man [sic] with himself." Thinking is also one of the most fragile features of human consciousness. Arendt is concerned with the ethical practice, which may be drained of the vitality of "the good" once this inner dialogue is no longer central to people's lives. Once the prospect of who I would have to live with in myself is no longer a concern, the consideration of what I owe others is diminished. Thinking will atrophy in an environment that lacks the stillness that allows us to engage in inner dialogue or, more ominously, in a social environment where distrust among people makes inner and outer conversation problematic. Arendt's emphasis is guided by the Socratic demand for "examined lives" and Kant's notion of the "enlargement of the mind" that are critical to the faculty of judgment. How is the Internet altering this? Waldron $(2007,2)$ argues that within the world of social networking:

paraphernalia of thoughtlessness is legion. Clichés and jargon, stock phrases and analogies, dogmatic adherence to established bodies of theory and ideology, the petrification of ideas - these are all devices designed to relieve the mind of the burden of thought, while maintaining an impression of intellectual cultivation.

Smith $(2010,3)$ is also quite candid in her criticism of this virtual world, arguing that:

when a human being becomes a set of data on a website like Facebook, he or she is reduced. Everything shrinks. Individual character. Friendships. Language. Sensibility. In a way it's a transcendent experience: we lose our bodies, our messy feelings, our desires, our fears... 500 million sentient people entrapped in the recent careless thoughts of a Harvard sophomore.

Language, thought and meaning are central to philosophical investigations about our conceptual understanding, and of our gestures of communication. The transformation of the public sphere brought about by communicative technology may involve a new "linguistic turn" where, as Judt $(2010,1)$ describes, "pithy illusion substitutes for exposition" - if so where to for communicative reason? To what extent do the rules of discourse ethics, as Habermas has clearly articulated, need to be re-thought or perhaps even deconstructed? We may have extended the domain of communicative deliberation but are really talking to each other? 


\section{Note:}

1. A term largely borrowed from Benjamin and his Arcades Project referring to Paris as like a magic lantern show of optical illusions - rapidly changing size and blending into one another. Marx also employed the term to refer to the deceptive appearances of commodities as "fetishes." In literary criticism it also refers to shifts in thought about consciousness and the individual person: also a gothic motif signifying the fluidity between the psyche and reality.

\section{References:}

Arendt, Hannah. 1993. Between Past and Future: Eight Exercises in Political Thought. New York: Penguin Books.

Benhabib, Seyla. 2010. On the Public Sphere, Deliberation, Journalism and Dignity. <http://www. resetdoc.org/story/00000000965>

Benkler, Yochai. 2007. The Wealth of Networks. New Haven: Yale University Press.

Burke, Peter. 1993. The Art of Conversation. Cambridge: Polity Press.

Carr, Nicholas. 2010. The Shallows: What the Internet Is Doing to Our Brains. New York: Norton.

Chatfield, Tom. 2010. The Age of Risk-free Internet Use May be Coming to an End. <http://www. independent.co.uk/opinion/commentators/tom-chatfield-2159568.html>

Clark, David. 2010. Complaint and Request for Inquiry and Injunctive Relief Concerning Unfair and Deceptive Mobile Marketing Practices. <http://www.democraticmedia.org/book/export/ html/378>

Cross, David. 2009. Australian Covert Bullying Prevalence Study. Perth: Edith Cowan University. <www.deewr.gov.au/Schooling/National Safe Schools/Pages/research.aspx>

DCITA. 2005. Department of Communications, Information Technology and the Arts. The Social Impact of Mobile Phone Use in Australia: A Review of Data Sources. Communications Research University, Canberra, Australian Government.

Farrell, Henry. 2010. Participation and Polarisation in the Networked Public Sphere. <http://publius. cc/category/authors/henry_farrell>

Gabbard, David. 2010. Mediating Democracy: What Robert Putnam Wouldn't Tell Us in Bowling Alone. <http://www.epluribusmedia.org/columns/20060707gabbard.html.>

Graham, Gordon. 2000. The Internet: A Philosophical Inquiry. London: Routledge.

Hannay, Alistair. 2005. On the Public: Thinking in Action. New York: Routledge.

Hindman, Matthew. 2009. The Myth of Digital Democracy. Princeton: Princeton University Press.

Judt, Tony. 2010. Words. <http://www.nybooks.com/articles/archives/2010/jul/15/words/>

Keane, Bernard. 2010. Twitter and the Prosaic Reality of Digital Democracy. <http://www.crikey.com. au/2010/06/07/keane-twitter-and-the-prosaic-reality-of-digital-democracy/>

Levy, Pierre. 1997. Collective Intelligence: Mankind's Emerging World in Cyberspace. New York: Plenum Press.

Petersen, Charles. 2010. Google and Money. <http://www.nybooks.com/articles/archives/2010/ dec/09/google-and-money/>

Postman, Neil. 2005. Amusing Ourselves to Death: Public Discourse in the Age of Show Business. New York: Penguin.

ReachOut. 2010. Cyberbullying: What is It and How to Get Help. <http://au.reachout.com/find/ articles/cyberbullying>

Rorty, Richard. 1993. Human Rights, Rationality, and Sentimentality. In S. Shute and S. Shute (eds.), Human Rights: The Oxford Amnesty Lectures, 111-134. New York: Basic Books.

Sager, Alex. 2010. A Plea for (the Philosophy of) Leisure. Philosophy Now 81, 27-28.

Sandbothe, Mike. 1999. Media Temporalities of the Internet: Philosophies of Time and Media in Derrida and Rorty. Al \& Soc 13, 4, 421-34.

Shirky, Clay. 2010. Cognitive Surplus: Creativity and Generosity in a Connected Age. Penguin Press: New York.

Smith, Zadie. 2010. Generation Why? <http://www.nybooks.com/articles/archives/2010/nov/25/ generation-why/?> 
Sunstein, Cass. 2001. The Daily We. <http://bostonreview.net/BR26.3/sunstein.php>

Sunstein, Cass. 2006. The Law of Group Polarization. In J.Fishkin and P.Laslett (eds.), Debating Deliberative Democracy, 80-101. Oxford: Blackwell.

Thompson, Clive. 2007. Clive Thompson on Outboard Memory. <http://www.endofcyberspace. com/2007/11/clive-thompson-.html>

Thompson, Clive. 2009. On the New Literacy. <http://www.wired.com/techbiz/people/ magazine/17-09/st_thompson.>

Waldron, Jeremy. 2007. What Would Hannah Say? <NYRBhttp://www.nybooks.com/articles/ archives $/ 2007 / \mathrm{mar} / 15 /$ what-would-hannah-say/?page=2>

Yar, Majid. 2000. Hannah Arendt's Two Theories of Political Judgment. Philosophy \& Social Criticism $26,2,1-27$. 